\title{
Reflexiones sobre diversas cuestiones cooperativas (análisis principal bajo Ley Vasca)
}

\author{
Iñigo Nagore \\ Abogado economista
}

Sumario: 1. Introducción. 2. De los Registros cooperativos. 2.1. El acceso a la publicidad registral. 2.2. Diferentes técnicas registrales. 2.3. Necesidad de dos certificaciones negativas de denominación para la constitución. 3. Cambio de ámbito territorial: domicilio y ámbito de aplicación. 4. Operaciones con terceros. 5. Socios de duración determinada. 6. Reglamento de Régimen Interno. Rango y alcance. 7. Aportaciones voluntarias. 8. Capitalización de resultados. Votos por clases de socios. 9. Rehusabilidad a la devolución de las aportaciones en caso de baja. 10. Distintos tipos de interés a las aportaciones obligatorias. 11. Afloración de plusvalías. 11.1. Ventas de activos. 11.2. Sociedades en el extranjero. Socios. Operaciones con terceros. 12. Efectos de las ventas de activos antes o después de acordar la liquidación. 13. Contabilidad y ajustes en patrimonio. 14. Repartibilidad de fondos constituidos por estatutos o acuerdo de Asamblea General como irrepartibles. 15. Problemas de descapitalización derivados de jubilaciones de socios trabajadores. Necesidades de capital para el establecimiento de cooperativas de trabajo asociado industriales fuertes. 16. Transformación y homologación. 17. Cambio de clase. 18. Cooperativas mixtas. 18.1. Porcentaje de capital y ajustes. 18.2. Control mediante el socio colaborador. 19. Cooperativización de empresas mercantiles filiales, normalmente en el extranjero, propiedad de la cooperativa.

Resumen: Desde la experiencia del autor se realiza una reflexión sobre diversas cuestiones Cooperativas, a su juicio, problemáticas, analizando el marco legal y en algunos casos reflexionando sobre posibles regulaciones alternativas. Es un artículo abierto al debate para que se puedan proponer soluciones y alternativas que mejoren puntos concretos de la regulación del sistema cooperativo.

Palabras clave: Registros cooperativos. Certificaciones negativas de denominación. Cambio de ámbito territorial. Operaciones con terceros. Socios de duración determinada. Reglamento de Régimen Interno. Régimen económico. Aportaciones voluntarias. Capitalización de resultados. Rehusabilidad del capital. Distintos tipos de interés. Afloración de plusvalías. Efectos de las ventas de activos antes o después de acordar la liquidación. Contabilidad y ajustes en pa- 
trimonio. Repartibilidad de fondos constituidos como irrepartibles. Descapitalización de cooperativas. Transformación. Cambio de clase. Cooperativización de la internacionalización. Cooperativas mixtas. Ley de Cooperativas de Euskadi. Ley de Cooperativas.

Abstract: From the experience of the author, a reflection is made on various controversial - in his opinion problematic - questions regarding the law of Spanish cooperatives, analyzing the current legal framework and in some cases reflecting on possible alternative regulations. It is an article open to debate so that solutions and alternatives can be proposed that improve specific points of the regulation of the cooperative system.

Keywords: Cooperative records. Negative certification of denomination. Change of territorial scope. Operations with third parties. Fixed-term partners. Internal regulations. Economic system. Voluntary contributions. Capitalization of results. Rejection of capital. Different types of interest. Realization of capital gains. Effects of the sale of assets prior and after agreeing the liquidation. Accounting and adjustments in equity. Distribution of funds constituted as undistributable. Decapitalization of cooperatives. Transformation. Class change. Cooperativization of internationalization. Mixed cooperatives. Law of Cooperatives of Euskadi. Law of Cooperatives. 


\section{Introducción}

El presente artículo trata de reflexionar sobre diversas cuestiones Cooperativas que me he encontrado a lo largo de más de 25 años de ejercicio profesional en el sector, tanto formando a socios, rectores y alumnos u otros, como defendiendo, asesorando o siendo parte del Consejo rector de cooperativas, tanto a socios como a Cooperativas o actuando como árbitro del Servicio del Consejo Superior de Cooperativas de Euskadi/Bitartu.

Trataré de exponer diversas cuestiones, para mi problemáticas, analizando el marco legal y en algunos casos reflexionando sobre posibles regulaciones alternativas. No se trata de defender la bondad de una u otra solución, sino que animar a que otros cooperativistas y/o juristas cooperativos opinen y contrasten, para que a través de ese debate se puedan proponer soluciones y alternativas que mejoren el sistema.

El debate sobre puntos concretos no debe entenderse, en ningún caso, como un cuestionamiento de un modelo que funciona, crea riqueza e integra a las personas que lo conforman en un proyecto común.

\section{De los Registros cooperativos}

\subsection{El acceso a la publicidad registral}

El actual sistema autonómico establece un sistema dual en el que por un lado se encuentran las cooperativas bajo normativas autonómicas y por otro, las escasas, cooperativas bajo ley estatal. El ámbito de la Ley estatal de Cooperativas viene definido en su artículo dos:

«Artículo 2. Ámbito de aplicación. La presente Ley será de aplicación:

A) A las sociedades cooperativas que desarrollen su actividad cooperativizada en el territorio de varias Comunidades Autónomas, excepto cuando en una de ellas se desarrolle con carácter principal.

B) A las sociedades cooperativas que realicen principalmente su actividad cooperativizada en las ciudades de Ceuta y Melilla.»

No obstante, dado las materias que aparecen reguladas tangencialmente en la misma, habrá que entender que respecto a estas materias (por ejemplo, su artículo 87 cuestiones contenciosas en lo que se refiere en las cooperativas de trabajo asociado) sigue teniendo un carácter general. 
Centrándonos en la realidad de los Estatutos de Autonomía, y dejando aparte la cuestión de si tiene sentido jurídico y de mercado el actual sistema de fraccionamiento, que hace que algunas comunidades autónomas tengan Cooperativas de alguna clase que se puedan contar, en el mejor de los casos, con los dedos de una mano, es preciso reflexionar sobre los efectos del sistema en la publicidad registral y, si es posible mejorar la misma, sin cambiar el sistema.

En la actualidad, para obtener información registral de una cooperativa española debemos, en primer lugar, saber bajo qué ley autonómica o estatal se encuentra, a fin de dirigirnos al registro correspondiente en busca de la información.

La información que vamos encontrar dependerá de las exigencias que la ley aplicable establezca.

En Cooperativas, que compiten en el mercado contra diversas fórmulas mercantiles, y que en algunos casos poseen sociedades mercantiles (hasta el 100\% de ellas) no encontramos justificaciones jurídicas para que esa información pública, sea distinta o pueda serlo, al del resto de las sociedades y, peor aún, distinta entre si.

A veces es necesario que un extranjero nos haga preguntas muy básicas sobre nuestro sistema jurídico para que al explicarlo nos demos cuenta de que el mismo puede ser fácilmente mejorable. Recordando una llamada de una empresa extranjera que antes de firmar un acuerdo de colaboración con una cooperativa española quería conocer las cuentas anuales de esta y no era capaz de obtenerlas en el registro mercantil, fue preciso explicarle que las cooperativas (con las excepciones previstas) no depositan sus cuentas en el citado registro. A partir de ahí indicarle que se me facilitaba el domicilio social o el código de identificación fiscal, podría centrar mi búsqueda en una comunidad autónoma concreta y, en su caso, adicionalmente, ver si estaba bajo legislación estatal. Que, una vez averiguado dónde estaba, dependeríamos de las exigencias que su regulación autonómica haya establecido en relación del depósito de cuentas, o si había hecho una referencia genérica a los requisitos de la legislación mercantil y, posteriormente, estaríamos a ver si efectivamente la cooperativa había realizado dicho depósito o, si por ausencia de medios o mecanismos de control autonómico, la misma no había sido efectuada y nada había sucedido. El cliente no llegaba a comprender como una empresa, que facturaba lo que aquella Cooperativas facturaba y que empleaba al número de trabajadores que aquella cooperativa empleaba, no estuviera obligada, a presentar sus cuentas, de una forma clara y homogénea, en un registro público y accesible.

Con el actual sistema de reparto competencial y sin proponer una reforma del mismo, creemos posible y necesario que las Administracio- 
nes públicas autonómicas y central trabajen bajo el principio de cooperación para facilitar las gestiones a los ciudadanos (p.e. ventanilla única). Con independencia de cuál sea la formula técnica elegida y el soporte jurídico de la misma, parece evidente que un punto único de acceso a la información registral de cualquier sociedad que opere en España (bajo la fórmula jurídica que sea) no puede ser entendido como un ataque a los regímenes competenciales, sino como una mera facilitación de un acceso a una información que debe ser pública.

En este sentido puede discutirse si un sistema informático tipo espejo ( se reflejan los datos de un registro en el otro), en el cual se recojan en el mercantil la información del registro de cooperativas y/o viceversa, puede ser la mejor opción; o discutirse si ese sistema debe extenderse a la totalidad de las cooperativas o, al menos, a las que superan ciertos umbrales, que pueden ser los mismos que se determinen para establecer la obligación de auditoría; o discutirse si los efectos para aquellas cooperativas que no depositen, deben ser comunes para todas ellas, y posiblemente iguales a los que se establezcan para otras fórmulas jurídicas.

Hemos hablado del depósito, pero creemos que esa información registral debe abarcar la totalidad de los actos inscribibles, y que sería conveniente que los actos escribibles fuesen, al menos, los mismos que se exigen a otro tipo de sociedades.

Quedaría una pregunta por responder: si se beneficia a las cooperativas defendiendo lo contrario. Creemos sinceramente que la respuesta es negativa.

\subsection{Diferentes técnicas registrales}

Otra cuestión cooperativa, que me ha surgido durante estos años, es la distinta técnica registral usada entre el Registro de Cooperativas de Euskadi, en el caso concreto, que comento y el Registro Mercantil. La cuestión surge de la amplitud del asiento que uno y otro realizan para inscripciones similares. Por ejemplo, una modificación de un artículo estatutario se recoge un registro con la indicación de que la cooperativa en una Asamblea General de fecha tal, según consta en escritura, modificó tal o tales artículos los estatutos sociales, sin incorporar el contenido de los artículos modificados (se queda con una copia, ahora simple, de la modificación que la servirá de apoyo), mientras que en el registro mercantil si se transcribe el contenido del citado artículo.

De nuevo cuando se pide información registral de la cooperativa, mediante una nota simple, te encuentras con que tal artículo se ha mo- 
dificado, pero para tener acceso al texto es preciso solicitarlo de forma expresa y que el registro acuda a la copia de la escritura que conserva.

El problema se agudiza en los supuestos de transformación, al exigir el registro mercantil un certificado expedido por el registro de cooperativas con los asientos que quedan vigentes y transcribiendo literalmente el contenido de los mismos. La idea subyacente es permitir al registro mercantil, en base al certificado emitido, inscribir dichos asientos que deben permanecer vigentes una vez acordada la transformación. La solución práctica supone que el registro de cooperativas, además de expedir el citado certificado debe acompañar copias de las escrituras que sirven de base a los asientos transcritos de forma que el mercantil pueda, en base a ambos, inscribir la información necesaria de la nueva sociedad.

Es un problema de técnica registral. ¿Se puede solucionar? Creemos que como en el caso anterior si, y creemos que, para beneficio de terceros, la información pública que se facilita en los distintos registros debería ser homogénea y de acceso inmediato.

2.3. Necesidad de dos certificaciones negativas de denominación para la constitución de la cooperativa

Cuando queremos constituir una cooperativa, bajo ley vasca, es necesario solicitar una certificación negativa de denominación al Registro de Socidades Cooperativas estatal y otra, al Registro de Cooperativas de Euskadi.

Sigue siendo necesario el doble certificado pese a que la Ley estatal establece:

"Artículo 109. Registro de Sociedades Cooperativas.

(...) Igualmente, el Registro de Sociedades Cooperativas emitirá la certificación negativa de denominación, previa coordinación con el Registro Mercantil Central así como con los demás Registros de Cooperativas, según las disposiciones que se establezcan al efecto.»

Sin perjuicio de que las calificaciones entre uno y otro puedan ser diversas (y he tenido calificaciones diversas en los dos sentidos, que el particular debe recurrir o, en aras a la celeridad de la constitución, más frecuentemente obligan a solicitar nuevas), resulta criticable que cuando se camina a nivel europeo en una simplificación de cargas administrativas, hacia una ventanilla única con la Administración, sea necesario realizar dos solicitudes. Debería trabajarse en un punto único 
de solicitud y dejar que sean las Administraciones las que cooperen o coordinen, no pasando cargas administrativas innecesarias a los administrados.

Todo ello sin perjuicio de que pueda también carecer de sentido la existencia de sociedades mercantiles, asociaciones, fundaciones, cooperativas... con idéntica denominación, sin que la Administración establezca un sistema común de otorgamiento y registro de denominaciones, a modo de registro de denominaciones de personas jurídicas.

\section{Cambio de ámbito territorial: domicilio y ámbito de aplicación}

El artículo tres de la LCE regula el domicilio social.

«Artículo 3. Domicilio social.

La cooperativa tendrá su domicilio social, dentro del territorio de la Comunidad Autónoma del País Vasco, en el lugar donde realice preferentemente las actividades con sus socios o donde centralice la gestión administrativa y la dirección empresarial.»

Y en la Ley estatal:

«Artículo 3. Domicilio.

La sociedad cooperativa fijará su domicilio social dentro del territorio español, en el lugar donde realice principalmente su actividad o centralice su gestión administrativa y dirección.»

Y ello siempre que resulte de aplicación (Ley estatal):

«Artículo 2. Ámbito de aplicación.

La presente Ley será de aplicación:

A) A las sociedades cooperativas que desarrollen su actividad cooperativizada en el territorio de varias Comunidades Autónomas, excepto cuando en una de ellas se desarrolle con carácter principal.

B) A las sociedades cooperativas que realicen principalmente su actividad cooperativizada en las ciudades de Ceuta y Melilla.»

El criterio, se separa del mercantil en el que son los socios los que deciden, en la constitución, o en posteriores Juntas (si es que acuerdan modificarlo) donde quieren que radique el domicilio social.

El marco competencial autonómico, hace necesario que se introduzca un criterio más fiscal que societario, de "domicilio efectivo», a fin de evitar que una cooperativa con sede formal en otra Comunidad 
Autónoma puede estar en la práctica operando con diferente regulación. De forma que se evite que las cooperativas puedan elegir la ley autonómica aplicable, con independencia de donde tengan efectivamente el domicilio efectivo.

Se obliga por la Administración, sin que quepa decisión de los socios, a fijar el domicilio en ese lugar. Supuestos transfronterizos quedan obviados (por ejemplo, una cooperativa vasca en el que la mayor parte de la actividad cooperativizada se realizara en el sur de Francia).

Con el «preferentemente» se posibilita, en la práctica (dada la ausencia de elementos de control y la poca voluntad de perder cooperativas propias), que se pueden realizar operaciones en cualquier otro lugar y sin límite.

Para cambiar la ley autonómica aplicable, la cooperativa deberá modificar los estatutos adoptando el cambio de domicilio, adecuándolos a la nueva ley y además deberá trasladar su actividad cooperativa principal. Para cambiar a la Ley General bastará con adecuar los estatutos a dicha ley y ampliar sustancialmente el ámbito de actividad cooperativizada.

Dadas las diversas regulaciones existentes para la transformación y la liquidación, puede ser interesante para los socios la modificación previa de ley aplicable, a la adopción de cualquiera de esos acuerdos. En tal sentido, recuerdo una cooperativa con sede física junto a la frontera, en la que se planteó la posibilidad de trasladar su domicilio social a Hendaya de forma que pasase a estar regida por la regulación francesa, a fin de evitar la normativa de transformaciones vasca.

Las cooperativas puede que sean las fórmulas jurídicas menos deslocalizables, especialmente cuando se trata de agrarias o de trabajo asociado con grandes plantas industriales. No obstante, la viabilidad del cambio dependerá del tamaño y de los recursos de la cooperativa.

Creemos que debe perfeccionarse el sistema y abordarse la regulación de los cambios de domicilio o de ámbito de actuación, que conlleven un cambio de ley aplicable. Aun cuando se trate de operaciones poco frecuentes, creemos que no deben quedar en manos de diversas interpretaciones de dos administraciones, sea autonómica de origen y autonómica de destino o autonómica y estatal, en un sentido u otro.

\section{Operaciones con terceros}

Desde una tradicional limitación cooperativa a la realización de actividades con terceros, que llevaba a considerar los resultados de estas operaciones como extracooperativos, se han ido flexibilizando los lími- 
tes y su propio carácter de extracooperativo en diversas cooperativas vigentes.

La Ley de Cooperativas de Euskadi establece que:

«Artículo 5. Operaciones con terceros.

1. Las cooperativas podrán realizar su actividad cooperativa con terceros siempre que, sin estar expresamente prohibida por la ley y los Estatutos no lo impidan, tenga carácter accesorio o subordinado respecto a la operativa con los socios.

Se entenderá cumplido el requisito de accesoriedad o subordinación siempre que la cooperativa respete los supuestos o límites determinados legalmente para esa actividad con terceros.

2. Cuando por circunstancias no imputables a la cooperativa las operaciones de ésta con sus socios y con terceros, dentro de los supuestos o límites legales, supongan una disminución o deterioro de la actividad empresarial que ponga en peligro la viabilidad económica de la cooperativa, ésta podrá ser autorizada para iniciar o aumentar actividades y servicios con terceros por el plazo y hasta la cuantía que fije la autorización, en función de las circunstancias que concurran. La citada autorización se entenderá concedida si en el plazo de un mes desde la presentación de la solicitud no resuelve expresamente el Departamento de Trabajo y Seguridad Social.

3. En todo caso, las cooperativas de crédito y las de seguros habrán de cumplir en sus operaciones con terceros los requisitos y limitaciones de la regulación aplicable a su respectiva actividad financiera.»(el subrayado es mío).

Igualmente, en las cooperativas de trabajo asociado se mantienen limitaciones al número de trabajadores no socios, en cuanto que cooperativizado el trabajo, estos trabajadores por cuenta ajena no socios, significan operaciones con terceros. Este punto concreto, que en cada reforma legislativa se va flexibilizando, da lugar otros problemas a los que me referiré más adelante.

Hace unos años asesoraba una cooperativa agraria no vasca especializada en un monocultivo, a la que sus auditores habían advertido que el número de operaciones con terceros superaba el máximo establecido por la ley autonómica aplicable y corría el riesgo de ser descalificada.

Las causas subyacentes eran, por un lado, de éxito de gestión (por cuanto desde la parte comercial, principalmente exportaciones, se estaban realizando más ventas de las que se podían satisfacer con la producción de los socios) y, por otro, de jubilación de socios. El problema se ha agravaba por cuanto que la cooperativa venía a comercializar el $70 \%$ del producto (monocultivo) que se producía en la comunidad au- 
tónoma uniprovincial y sus socios representaban un porcentaje similar de la tierra dedicada a ese cultivo. Era una cooperativa saneada económicamente que había realizado importantes inversiones en naves industriales que había que amortizar. Además, se trataba de un producto cuya cosecha se comercializaba, mediante contratos de futuros, por lo que se vendían entre seis meses y nueve antes de que fuera producidas, por lo que si la cosecha era mala, la única forma de cumplir el contrato era comprando a terceros.

Solicitada la preceptiva autorización al órgano autonómico cooperativo correspondiente y presentada toda la documentación requerida, se advirtió por este que dado que la cooperativa no estaba en perdidas no podía autorizarse exceder el porcentaje de operaciones con terceros. La interpretación de "disminución de actividad que ponga en peligro su viabilidad económica» se hacía de forma literal, exigiéndose pérdidas existentes y no evitación de pérdidas futuras. Se recomendó a la cooperativa que se transformara y que dejara de ser cooperativa.

A nuestro modo de ver está interpretación tiene poco que ver con la promoción del cooperativismo, además de adolecer de una falta de conocimiento sobre las estructuras jurídicas alternativas. Hoy las cooperativas pueden constituir sociedades mercantiles, llegando hasta el 100 por 100 de su capital y conservando, siempre que obtenga la preceptiva autorización de la administración fiscal competente, su régimen fiscal especial.

Esto es, se sigue pensando que las cooperativas viven en un universo aislado y que obligatoriamente deben realizar todas sus operaciones, cooperativadas o no, a través de la cooperativa, cuando pueden realizarlo a través de mercantiles de la que participen totalmente $o$, en un porcentaje inferior, dejando al resto en manos de sus socios $u$ otros.

Al igual que una cooperativa de trabajo asociado puede constituir sociedades mercantiles en las que opere con un $100 \%$ de trabajadores por cuenta ajena. Formulación a la que nos referiremos luego y que ha servido, por ejemplo, para poder establecer plantas de producción, propiedad de cooperativas vascas, en el extranjero creando miles de puestos de trabajo.

Por ello, creemos que los actuales límites de operaciones con terceros, solo sirven para limitar las operaciones con terceros de aquellas cooperativas de escasos recursos o poco asesoramiento, siendo absolutamente ineficaces respecto de cualquier otra. En este sentido, el modo tradicional no funciona y debería reflexionarse sobre las formulas que permitan salvaguardar los valores cooperativos sin condenar a las cooperativas a no poder sobrepasar cierto tamaño. 


\section{Socios de duración determinada}

Introducida por primera vez, en el artículo 26, de la LCE:

«Artículo 26. Baja voluntaria.

(...)

2. La pertenencia del socio a la cooperativa tendrá carácter indefinido.

No obstante, si lo prevén los Estatutos y se acuerda en el momento de la admisión, podrán establecerse vínculos sociales de duración determinada. Los derechos y obligaciones propios de tales vínculos serán equivalentes a los de los demás socios y serán regulados en los Estatutos. El conjunto de estos socios no podrá ser superior a la quinta parte de los socios de carácter indefinido de la clase de que se trate, ni de los votos de estos últimos en la Asamblea General, salvo en las cooperativas de trabajo asociado o en las que, siendo de otra clase, tengan socios de trabajo, que podrán superar dichas proporciones siempre que el número de horas/año de trabajo realizadas en conjunto por los socios de duración determinada, y los trabajadores por cuenta ajena, no llegue al 50\% del total de horas/año realizadas por los socios trabajadores o de trabajo de carácter indefinido.

Los socios trabajadores o de trabajo titulares de contratos societarios de duración determinada que acumulen un periodo de tres años en esa situación tendrán la opción de adquirir la condición de socio de duración indefinida, y si dicho periodo alcanza cinco años la adquirirán en todo caso, para lo que deberán cumplir los demás requisitos estatutariamente establecidos para los socios de duración indefinida.»

Sin perjuicio de la mala colocación sistemática de este tipo de socios, que aparecen no en clases de socios sino dentro de las bajas, me quiero referir a diversos problemas de socios trabajadores de duración determinada en cooperativas de trabajo asociado que he constatado en el periodo.

Si aceptamos la idea subyacente de que mediante esta modificación se pretendía que las cooperativas de trabajo asociado pudieran cooperativizar las relaciones laborales de carácter temporal, deberíamos discutir sobre si se han alcanzado los objetivos y analizarse como se están utilizando.

En primer lugar, me referiré al problema de cómo puede una cooperativa de trabajo asociado, en cuyos estatutos haya optado por el régimen especial de trabajadores autónomos convencer a un trabajador para que acepte convertirse en socio de duración determinada, no teniendo desempleo y arriesgándose a que una posible imputación de pérdidas reduzca su retribución, especialmente en períodos de crisis económica 
donde no esté, mínimamente garantizado, que este socio vaya a acabar convirtiéndose en socio trabajador de carácter indefinido. En este escenario es muy difícil que un trabajador que tenga cualquier otra opción laboral acepte convertirse en socio de duración determinada.

En segundo lugar, están los problemas del uso práctico de la figura. Contratos societarios con aplazamiento del desembolso de la aportación obligatoria del socio de duración determinada superiores a la duración del propio contrato, renovaciones de contratos en las que se renegocia el plazo de desembolso de la aportación, mezclas de contratos societarios con contratos laborales, imputaciones de pérdidas al capital que haría que el socio de duración determinada debiera realizar nuevas aportaciones o causar baja (cuando la cooperativa no quiere que cese la prestación laboral), falta de formación cooperativa previa que hace que el socio trabajador realmente no sepa a qué se está comprometiendo...

Creemos que la incorporación de la posibilidad fue buena, pero que aprendiendo de la experiencia debe incrementarse la regulación, modulando algunos aspectos y corrigiéndose otros.

\section{Reglamento de Régimen Interno. Rango y alcance}

Otro de las cuestiones tradicionales en el mundo cooperativo, especialmente en trabajo asociado, es el Reglamento de Régimen Interno.

En la letra j) del número tres del artículo 31 de la LCE, se establece como competencia de la Asamblea General la «Aprobación o modificación del Reglamento Interno de la cooperativa».

Su naturaleza jurídica no está definida en la LCE, siendo frecuente que incorporen al mismo todas las cuestiones de la parte laboral de la relación sociolaboral, que en una relación laboral externa estarían dentro de un Convenio Colectivo, así en las materias comprendidas en los artículos 101,102 y 103 de la LCE.

Pero adicionalmente suelen regular otras materias que aparecen en los estatutos sociales, en concreto las exigidas en el contenido mínimo de los estatutos del artículo 13, especialmente de la letra f) en adelante.

La cuestión es que el reglamento interno no deja de ser un compendio de acuerdos societarios numerado por artículos y limitado a las materias que la ley atribuye como competencia a la Asamblea General, sea en el artículo 31 o en otros.

El reglamento no está sometido a la regulación de modificación de estatutos, no existiendo por ello informe justificativo de modificación, ni es calificado por el registro, ni al no ser inscribible, tampoco está sujeto al control de legalidad del letrado asesor del artículo 73. 
Creo que debe reflexionarse sobre la conveniencia de establecer un sistema de control que permite detectar cuando a través del reglamento se están regulando cuestiones que exigirían una regulación estatutaria. Adicionalmente, creo que debería discutirse si debería controlarse que a través del reglamento no se estuviese ampliando las competencias de la Asamblea General, limitadas según el artículo 31.4 («únicamente podrá tomar acuerdos obligatorios en materias que esta ley no considere competencia exclusiva de otro órgano social») a las de la lista del 31.3.

También creo que debe debatirse sobre la conveniencia de que en los casos que exista letrado asesor su control de legalidad se extienda sobre el reglamento y, creo que también debe debatirse sobre la posibilidad de una inscripción del reglamento en el Registro de Cooperativas, sea obligatoria o voluntaria, a fin de garantizar el control administrativo sobre la legalidad del mismo.

Adicionalmente, creo que debería considerarse la necesidad de que la modificación del reglamento exija requisitos formales similares a los de la modificación de estatutos (informe justificativo, con el mismo contenido que la modificación estatutaria), constancia clara en la convocatoria de los artículos a modificar y otros.

\section{Aportaciones voluntarias}

Se regulan, en la forma tradicional, en la Ley de Cooperativas de Euskadi:

«Artículo 59. Aportaciones voluntarias al capital social.

1. La Asamblea General podrá acordar la admisión de aportaciones voluntarias al capital social realizadas por los socios, fijando las condiciones de las mismas.

2. Los administradores podrán aceptar en todo momento aportaciones voluntarias de los socios al capital social, si bien la retribución que establezca no podrá ser superior a la de las últimas aportaciones voluntarias al capital acordadas por la Asamblea General o, en su defecto, a la de las aportaciones obligatorias.»

En similar sentido, la Ley estatal establece:

«Artículo 47. Aportaciones voluntarias.

1. La Asamblea General y, si los Estatutos lo prevén, el Consejo Rector, podrá acordar la admisión de aportaciones voluntarias al ca- 
pital social por parte de los socios, si bien la retribución que establezca no podrá ser superior a la de las últimas aportaciones voluntarias al capital acordadas por la Asamblea General o, en su defecto, a la de las aportaciones obligatorias.

2. Las aportaciones voluntarias deberán desembolsarse totalmente en el momento de la suscripción y tendrán el carácter de permanencia propio del capital social, del que pasan a formar parte.

3. El Consejo Rector podrá decidir, a requerimiento de su titular, la conversión de aportaciones voluntarias en obligatorias, así como la transformación de aportaciones obligatorias en voluntarias cuando aquéllas deban reducirse para adecuarse al potencial uso cooperativo del socio.»

En estos años de asesoramiento debo reconocer que las aportaciones voluntarias que he conocido han sido el resultado de capitalizaciones de retornos acordados por la Asamblea General, en distintas épocas, bajo distintas leyes. Si la Asamblea podía constituir un fondo de reserva voluntario, se entendía que aquellos retornos que se quisieran capitalizar y no fuesen aportaciones obligatorias debían ser aportaciones voluntarias.

El problema suele agravarse por cuanto que conforme a los modelos tipo de estatutos sociales, se suele indicar en los mismos, que la Asamblea que acuerde las mismas deberá fijar el tipo de interés de retribución y el vencimiento.

Así se nos plantean varias cuestiones, a nuestro modo de ver, no resueltas por la Ley:

- Si la voluntad de suscribir las aportaciones voluntarias por parte de los socios debe ser un acto individual de cada uno de ellos o, por el contrario, es posible que la Asamblea tome un acuerdo colectivo (por ejemplo, el destino de parte de los resultados). Nos referiremos luego a una cuestión similar cuando tratemos la capitalización obligatoria de retornos.

- Si en los Estatutos de las vascas se establece que se fije el vencimiento de las aportaciones voluntarias y este no es fijado, ¿serán esas aportaciones voluntarias exigibles a la vista y con independencia de la baja del socio en la cooperativa (siguiendo el socio en la cooperativa)?

\section{Capitalización de resultados. Votos por clases de socios}

Establece el artículo 58 de la Ley estatal de cooperativas, en su apartado cuarto: 
«4. El retorno cooperativo se acreditará a los socios en proporción a las actividades cooperativizadas realizadas por cada socio con la cooperativa. Los Estatutos o, en su defecto, la Asamblea General, por más de la mitad de los votos válidamente expresados, fijarán la forma de hacer efectivo el retorno cooperativo acreditado a cada socio.»

En la misma línea se pronuncia del artículo 67 de la Ley de Cooperativas de Euskadi, aunque sin hacer mención expresa a cómo se acordará la forma de hacer efectivo el retorno:

«Artículo 67. Distribución de excedentes.

1. Los excedentes netos, una vez deducidas las cantidades que se destinen a compensar pérdidas de ejercicios anteriores y atender los impuestos exigibles, constituirán los excedentes disponibles.

2. Anualmente, de los excedentes disponibles se destinará:

a) Un veinte por ciento, como mínimo, al Fondo de Reserva Obligatorio.

b) Un diez por ciento, como contribución obligatoria para educación y promoción cooperativa y a otros fines de interés público.

c) El resto estará a disposición de la Asamblea General, que podrá distribuirlo de la forma siguiente:

1. Retorno a los socios. (...)»

Se sigue el sistema tradicional, en la regulación cooperativa, por el que la Asamblea General es la que decide la forma de reparto retorno, si se capitaliza o distribuye y, en general, si se aplica a otros fondos de forma que no haya retorno.

Aun cuando entiendo el principio cooperativo de la soberanía de la Asamblea General, desde un punto de vista de derecho societario llama la atención que socios que no han participado, en la generación del mismo ni van a tener derecho a recibir retorno alguno (p.e. socios inactivos/no usuarios o normalmente también los colaboradores) tengan derecho a pronunciarse es una decisión que, a priori, no les va a afectar y que, en general, va reducir (distribuyo) o mantener (no distribuyo) los recursos financieros propios de la cooperativa de la que son socios, sin que el acuerdo les pueda beneficiar directamente en ningún caso (por su ausencia de actividad cooperativa).

Por tanto, en este punto tenemos socios que deciden sobre cuestiones que no les afectan directamente. Creo que debería doctrinalmente discutirse si esta es la mejor posibilidad de las existentes o si hay otras más acordes con la defensa de los derechos que realmente se van a ver afectados por el acuerdo y ello, aún siendo cierto que un excesivo reparto de retornos puede llevar a una descapitalización de la cooperativa que acabe afectando al resto de los socios. 
Otra cuestión, conexa con lo anterior, es si el acuerdo mayoritario de la Asamblea General debe obligar por igual forma a socios que irían a recibir cantidades distintas en concepto de retornos. Realmente el problema, a mi juicio, se centra en aquellos casos en los cuales la Asamblea General acuerda la capitalización de los retornos. Creo necesario reflexionar sobre si la defensa de la soberanía de la Asamblea General debe, en estos supuestos, prevalecer al derecho individual de los socios al retorno.

El retorno es la aplicación del resultado (dotados los fondos obligatorios y otros) según la actividad cooperativa realizada. Podríamos diferenciar los supuestos en los que los estatutos de la cooperativa establece la obligación de cooperativista del $100 \%$ de la actividad del socio (por ejemplo en bodegas cooperativas, la entrega del $100 \times 100$ de la producción de uva a la bodega) de aquellos en lo que esto no sucede.

Claramente no vemos sentido que un socio que ha preferido comercializar su uva al margen de la cooperativa (salvo unos pocos kilos) pueda obligar al socio que ha realizado una mayor comercialización de sus kilos en la cooperativa a que capitalice el retorno obtenido. De forma que esté obligando a que este socio el que acabe financiando la actividad cooperativa futura.

En este sentido, creo debiera valorarse una regulación que establezca que el derecho de voto respecto a la distribución de los retornos se realice en base a la actividad cooperativizada realizada por los socios. El mayor problema de esta solución es que estaría rompiendo el principio que tradicional de un hombre un voto.

Igual sucede en cooperativas en las que la mayoría de los socios realiza una actividad cooperativa mínima pero en conjunto tienen la mayoría societaria y pueden acordar obligando a los pocos que realmente realizan actividad. El conflicto de intereses subyacente en este tipo de situaciones creemos requiere un mayor debate.

Otra cuestión adicional es la capitalización obligatoria de retornos por acuerdo de Asamblea General, que lleva a cuentas de capital obligatorio de los socios con distintos importes. Esto ocasiona que si bien en la constitución de la cooperativa había unas aportaciones obligatorias similares, con los años dichas aportaciones pueden acabar siendo radicalmente diferentes.

Siendo el capital social un recurso retribuido a un tipo de interés, que no debe participar en la toma de decisiones, creo que debemos debatir sobre si realmente cabe obligar a que los socios mantengan cantidades distintas de este recurso de forma obligatoria, asumiendo los riesgos económicos que dicho mantenimiento conlleva (por ejemplo en un concurso de acreedores). 
Son cuestiones sobre las que creo debe realizarse un debate sereno que nos permita, en su caso, una mejor delimitación de los derechos individuales de los socios.

\section{Rehusabilidad a la devolución de las aportaciones en caso de baja}

Al hilo de la introducción en España de la Norma Internacional de Contabilidad número 32, instrumentos financieros: presentación, se introdujo en la normativa vasca la posibilidad de establecer en Estatutos que el órgano de administración de la cooperativa pudiese rehusar la devolución de las aportaciones en caso de baja.

Así, se modificó el artículo 57 de la LCE:

«Artículo 57. Capital social.

1. El capital social de la cooperativa estará constituido por las aportaciones de naturaleza patrimonial realizadas al mismo por los socios y socias, ya sean obligatorias o voluntarias, que podrán ser:

a) Aportaciones con derecho de reembolso en caso de baja.

b) Aportaciones cuyo reembolso puede ser rehusado incondicionalmente por la Asamblea o el Consejo Rector, según se prevea en los estatutos.

La transformación obligatoria de aportaciones con derecho de reembolso en caso de baja en aportaciones cuyo reembolso puede ser rehusado incondicionalmente por la cooperativa, o la transformación inversa, requerirá el acuerdo de la Asamblea General. El socio o socia disconforme podrá darse de baja, calificándose ésta como justificada.

1 bis. Los estatutos podrán prever que, cuando en un ejercicio económico el importe de la devolución de las aportaciones supere el porcentaje de capital social que en ellos se establezca, los nuevos reembolsos estén condicionados al acuerdo favorable del Consejo Rector.

El socio o socia disconforme con el establecimiento o disminución de este porcentaje podrá darse de baja, calificándose ésta como justificada.

En este supuesto, también serán de aplicación el apartado 4 del artículo 60, el apartado 1 del artículo 62 y el apartado 3 del artículo 94.»

En un momento de crisis económica y con gran número de socios a punto de jubilarse en las cooperativas de trabajo asociado que generarían un importante volumen de devolución de aportaciones y con ello unas necesidades que cubrir esa pérdida de financiación propia con financiación ajena, se realizó la anterior reforma. 
Al amparo de la citada norma, se entiende que sólo serán fondos propios/no exigibles, las aportaciones sociales sobre las que se haya establecido o se pueda establecer la rehusabilidad de la devolución, mientras que aquellas que se amparen en el régimen general anterior deberían tener el carácter de deuda (exigible), en vez de capital (no exigible). Se crea así una disociación entre capital a efectos societarios y capital a efectos contables, con efectos a la hora de la concesión de créditos por terceros, por cuanto sin reusabilidad puede considerarse a efectos contables que la sociedad no tiene fondos no exigibles ya que todos son exigibles en caso de baja.

Las Federaciones vascas de cooperativas enviaron diversos modelos, para realizar las modificaciones estatutarias que permitieran acordar la reusabilidad. En ellos se pretendía encontrar un equilibrio entre la posibilidad de rehusar el capital y el derecho del socio a recibir el mismo, una vez que ha ejercitado su derecho de baja (aplicación del principio de puerta abierta).

Así, es habitual en las cooperativas de trabajo asociado, que han introducido la rehusabilidad, que se establezcan garantías estatutarias, estableciendo para que la posibilidad se active deban existir unas circunstancias económicas adversas y estableciendo, adicionalmente, unas limitaciones relativas a la imposibilidad de repartir retornos, interés al capital o destino de los nuevos capitales, de los socios que se incorporen tras el acuerdo, al reembolso de las aportaciones rehusadas.

No obstante, todo lo anterior es un desarrollo estatutario que busca por un lado hacer menos gravosa la situación de unos socios que se incorporaron bajo el régimen legal anterior y que, de la noche a la mañana, por un una modificación de estatutos, ven como el Consejo rector puede acordar que no vayan a ver reembolsadas sus aportaciones.

En primer lugar, creemos que una modificación estatutaria de este tipo debería conceder al socio no sólo un derecho de separación y una calificación de la baja como justificada, sino también una devolución inmediata de las aportaciones. Las reglas de juego se varian sustancialmente por lo que debería permitirse al socio disidente causar baja en la cooperativa con devolución inmediata de las aportaciones.

No obstante, en algunas clases de cooperativas, como las de trabajo asociado, este derecho de separación podría no ser suficiente, por cuanto que el efecto adicional de la baja en la cooperativa es la pérdida del puesto de trabajo y ello puede ocasionar, en la práctica, que el teórico derecho sea impracticable. Por ello, creemos necesario reflexionar sobre cómo garantizar los derechos individuales de los socios cuando 
se pretende realizar una modificación estatutaria de este tipo. Máxime cuando los capitales a rembolsar pueden ser absolutamente distintos entre socios de la misma clase, como también pueden ser radicalmente distintas las edades de los socios, algunos próximos a jubilarse, en una cooperativa de trabajo asociado.

En segundo lugar, la rehusabilidad puede ser levantada. Tras la reforma legal y los años en los que más arreció la crisis económica, me he encontrado con los primeros casos en los que la situación económica permite el levantamiento del acuerdo de rehusabilidad de las aportaciones. El acuerdo, por un principio de prudencia, se suele adoptar cuando la cooperativa ha salido de la adversa situación económica. La paradoja es que de la lectura literal, de las garantías que se suelen establecer en estatutos para los socios mientras su capital está rehusado, resulta que levantada la rehusabilidad, la cooperativa y sus socios pueden tomar acuerdos que no podrían tomar con ella implantada, mientras el plazo temporal de devolución de aportaciones empieza a correr. El acuerdo de rehusabilidad se suele adoptar cuando se produce la baja del socio, con lo cual el plazo de reembolso no se inicia, iniciándose tan sólo cuando la rehusabilidad ha sido levantada.

Considero que debería reflexionarse sobre la conveniencia de que el plazo durante el cual el socio que causó baja ha tenido sus aportaciones rehusadas, compute dentro del general de reembolso de las aportaciones, de forma que, si ha superado en situación de rehusabilidad el plazo general de reembolso, el reembolso deba ser realizado de forma inmediata tan pronto se levanta el acuerdo de rehusabilidad, mientras que si ha estado en esa situación un plazo menor al de reembolso, la cooperativa debería realizar el reembolso como máximo en el tiempo que media hasta el plazo máximo legal.

\section{Distintos tipos de interés a las aportaciones obligatorias}

Establece la LCE, en su artículo 60:

«Artículo 60. Interés de las aportaciones.

1. Las aportaciones al capital social podrán devengar un interés en la cuantía que previamente establezca la Asamblea General, sin perjuicio de lo establecido en el número 2 del artículo precedente.

2. El interés no podrá exceder del interés legal más seis puntos.

3. La retribución de las aportaciones a capital estará condicionada a la existencia de resultados netos o reservas de libre disposición suficiente para satisfacerla. 
4. Si la Asamblea General acuerda devengar un interés a las aportaciones o destinar excedentes disponibles a retornos o a reservas repartibles, las aportaciones previstas en el artículo 57.1.b, cuyo reembolso hubiera sido rehusado por la cooperativa y cuyos titulares hubieran causado baja, tendrán una remuneración preferente que se establecerá en los estatutos sociales.»

Durante más de 25 años he trabajado bajo el supuesto de que la Asamblea General establecía anualmente el tipo de interés de las aportaciones obligatorias. Siendo el capital un recurso externo al servicio de la empresa, se retribuía a los socios que lo habían depositado conforme un tipo de interés: la retribución al capital.

En los últimos años, me encontrado con cooperativas, que han establecido retribuciones por tramos a las aportaciones obligatorias. Bajo el argumento de lo que no está prohibido está permitido, han establecido una retribución por tramos.

Si consideramos que las aportaciones al capital integran el capital social y, por tanto, corren el riesgo de perderse, no puedo ver la lógica de un sistema en el que se retribuya al capital de una forma decreciente.

Esto es, podría entender que la Asamblea General acuerde no retribuir por ejemplo los primeros $10.000 €$, siempre que todos los socios tengan esa cantidad y de forma que todos los socios se vean afectados de igual manera por el acuerdo y si el resto a tipo único. Lo que no acabo de ver es que la Asamblea General puede acordar por mayoría establecer tramos de retribución, por ejemplo, el primero cercano al máximo legal para prácticamente todos los socios, el segundo cercano a la mitad del máximo legal para aproximadamente un $20 \%$ de los socios y el tercero cercano a un $20 \%$ del máximo legal para aproximadamente un $5 \%$ de los socios. Y ello, sin contemplarse tan siquiera la posibilidad de que el socio solicite el reembolso de las aportaciones que entiende discriminadas en su retribución.

Son supuestos en los cuales la mayoría de los socios con capitales inferiores, está acordando una retribución que les favorece en detrimento de una minoría de socios con capitales más altos. Creemos que la posibilidad no debería admitirse, y que de admitirse debería establecerse el derecho del socio con capital superior a poder solicitar el reembolso del exceso (solución que por temas fiscales podría no ser suficiente cuando el coste fiscal de reembolso anulase la diferencia de tipos).

Además, creo no consideran el componente de mayor riesgo del socio que tiene más capital. 


\section{Afloración de plusvalías}

La LCE optó por la eliminación de la tradicional diferencia entre resultados cooperativos y extracooperativos, pasando a unos resultados únicos del ejercicio.

Debo manifestarme conforme con la eliminación entre un tipo y otro de resultados, pero creo que los efectos de la misma no han sido suficientemente valorados y afectan a distintos puntos a los que me referiré.

El artículo 66 LCE establece el criterio general para la determinación de excedentes netos, fijando el artículo 67 las posibilidades de distribución y el 68 y el 68 bis regulando los fondos sociales obligatorios y sus dotaciones.

Así:

"Artículo 66. Determinación de excedentes netos.

1. Para la determinación de los excedentes netos se aplicarán las normas y criterios establecidos para las sociedades mercantiles.

(...)

Artículo 67. Distribución de excedentes.

1. Los excedentes netos, una vez deducidas las cantidades que se destinen a compensar pérdidas de ejercicios anteriores y atender los impuestos exigibles, constituirán los excedentes disponibles.

2. Anualmente, de los excedentes disponibles se destinará:

a) Un veinte por ciento, como mínimo, al Fondo de Reserva Obligatorio.

b) Un diez por ciento, como contribución obligatoria para educación y promoción cooperativa y a otros fines de interés público.

c) El resto estará a disposición de la Asamblea General, que podrá distribuirlo de la forma siguiente:

1. Retorno a los socios.

2. Dotación a fondos de reserva voluntarios, con el carácter irrepartible o repartible que establezcan los Estatutos o, en su defecto, la Asamblea General.

3. Dotación adicional a los fines indicados en la letra b) del presente apartado, y, en su caso,

4. Participación de los trabajadores asalariados en los resultados de la cooperativa.

3. En tanto que el Fondo de Reserva Obligatorio no alcance un importe igual al cincuenta por ciento del capital social, podrán modificarse las cuantías obligatorias reguladas en los apartados 2.a) y 2.b), destinando un veinticinco por ciento al Fondo de Reserva Obligatorio y un cinco por ciento como contribución obligatoria. 
4. Los retornos se adjudicarán a los socios en proporción a las operaciones, servicios o actividades realizadas por cada socio con la cooperativa.

5. La cooperativa podrá reconocer y concretar en sus Estatutos, o por acuerdo de la Asamblea General, el derecho de sus trabajadores asalariados a participar en los resultados favorables. Esta participación tendrá carácter salarial y sustituirá al complemento de similar naturaleza establecido, en su caso, en la normativa laboral aplicable, salvo que fuese inferior a dicho complemento, en cuyo caso se aplicará este último.

Artículo 68. Fondos sociales obligatorios.

1. El Fondo de Reserva Obligatorio, destinado a la consolidación, desarrollo y garantía de la cooperativa, es irrepartible entre los socios, excepto en los supuestos expresamente previstos en esta ley.

2. Al Fondo de Reserva Obligatorio se destinarán necesariamente:

a) El porcentaje de los excedentes disponibles que establezca la Asamblea General, de acuerdo con lo establecido en el artículo precedente.

b) Las deducciones sobre las aportaciones obligatorias al capital social en caso de baja de socios.

c) Las cuotas de ingreso.

Artículo 68 bis. Contribución para educación y promoción cooperativa y otros fines de interés público.

1. La contribución obligatoria impuesta sobre los excedentes citada en el apartado 2.b del artículo 67 se destinará, en aplicación de las líneas básicas fijadas por los Estatutos o la Asamblea General, a alguna de las siguientes finalidades de interés público:

a) La formación y educación de sus socios y trabajadores sobre el cooperativismo, actividades cooperativas y otras materias no relacionadas con el puesto de trabajo.

b) La promoción de las relaciones intercooperativas, incluyendo la cobertura de gastos por la participación en entidades creadas para la promoción, asistencia, dirección común o actividades de apoyo entre cooperativas.

c) La promoción educativa, cultural, profesional y asistencial, así como la difusión de las características del cooperativismo, en el entorno social en que se desenvuelva la cooperativa y en la sociedad en general, y la promoción del uso del euskera.

d) La promoción de nuevas empresas cooperativas mediante aportaciones dinerarias a una entidad sin ánimo de lucro promovida por el movimiento cooperativo vasco.

2. El destino de esta contribución obligatoria podrá canalizarse, para las finalidades indicadas en las letras a), b) y c) del apartado anterior, a través de aportaciones dinerarias a entidades sin ánimo de 
lucro o a alguna de las entidades de intercooperación citadas en el apartado 1.b anterior.

Esta entrega a entidades intermediarias estará condicionada a su destino a las finalidades de interés público indicadas, a través de actuaciones de la propia entidad intermediaria o de otras personas físicas o jurídicas a las que dicha entidad destine los recursos recibidos.

3. La cooperativa no tiene poder de disposición sobre esta contribución, más allá de destinarla a las finalidades de interés público indicadas, siendo, en consecuencia, inembargable y debiendo figurar en el pasivo del balance.

4. A los fines previstos para esta contribución se destinarán las sanciones económicas que imponga la cooperativa a sus socios.

5. El importe de la referida contribución que no se haya destinado a las finalidades de interés público indicadas por la propia cooperativa deberá entregarse, dentro del ejercicio económico siguiente a aquel en el que se aprobó la distribución del excedente, a entidades sin ánimo de lucro para su destino a las finalidades de interés público establecidas para esta contribución.»

\subsection{Ventas de activos}

Si tradicionalmente la venta de ciertos activos, daba lugar a resultados extracooperativos que dotaban fondos obligatorios ahora en las cooperativas bajo LCE, y con las salvedades derivadas de los ajustes en patrimonio a los que luego me referiré, dicho resultados se integran dentro de las cuentas ordinarias y una vez dotados los fondos obligatorios, se pueden distribuir por la Asamblea General conforme a los criterios generales marcados en el artículo 67.

Por tanto, mientras que con el régimen tradicional las plusvalías latentes no afectaban a un socio que fuese a causar baja (al ser extracooperativas y deber integrarse cuando aflorasen en un fondo obligatorio), ahora resulta que la Asamblea puede llegar a acordar un reparto de hasta el $70 \%$ de las mismas.

Así, por ejemplo, si se vende un pabellón antes de mi jubilación, integrándose la plusvalía dentro de resultados del ejercicio, podré llegar a disponer como socio, si así lo acuerda la Asamblea General, de la parte que me toque del $70 \%$ que queda una vez restados los fondos obligatorios y si no se vende antes de que me jubile no recibiré nada.

Personalmente no tengo clara que la solución sea lógica, entre otras cosas porque es cierto que en la plusvalía del inmueble no existe una cooperativización de actividad que la genere, ni la plusvalía se genera necesariamente en el ejercicio que aflora (se materializa al producirse la venta pero en ejercicios anteriores puede haber sido hasta su- 
perior). Se mezclan criterios contables con criterios societarios y a mi modo de ver debería valorarse si el resultado es el más acorde.

Las plusvalías latentes respecto del valor de contabilización de los activos pueden ser valoradas en las sociedades de capital a la hora de establecer el valor de la acción o participación, mientras que en las cooperativas $y$, en tanto no se realice materialmente el resultado, la plusvalía no tiene ningún efecto a la hora de determinar el valor de las aportaciones de los socios.

Cuestión distinta, es el interés de los socios, en caso de que conocieran cuáles son los efectos económicos de la decisión, de realizar activos a fin de aumentar sus cuentas de capital. De hecho, me he encontrado con el supuesto de un gerente socio de una cooperativa de trabajo asociado que justo antes de su jubilación planteaba la venta de los inmuebles a un tercero, en una operación de venta con arrendamiento (lease back). La operación conllevaba un resultados del ejercicio muy superiores derivados de las plusvalías y posibilitaba, si se acordaba el retorno monitorizado de los mismos, que esté socio gerente pudiese incrementar sus capitales de cara a su inminente jubilación.

Cuando una regulación motiva de operaciones que no son naturales debemos plantearnos si dicha regulación debe ser modificada.

\subsection{Sociedades en el extranjero. Socios. Operaciones con terceros}

Una variante del anterior, que conlleva una mayor complejidad, es la de las cooperativas que tienen sociedades (plantas industriales de gran facturación y activos) en el extranjero.

Como en el caso de los inmuebles, las sociedades constituidas en el extranjero (como cualquier otro tipo de sociedad) están contabilizadas por el valor de adquisición. Mientras no se enajenan las participaciones o las acciones (normalmente se constituyen bajo fórmula mercantil), no aflora la posible plusvalía llegando a la matriz cooperativa únicamente los dividendos que se acuerden distribuir en la filial. Anualmente, si es que existen dividendos estos se integrarán en la cuenta de resultados de la cooperativa que podrán dar lugar a retornos. No obstante, podrían no repartirse dividendos engordándose la filial, sin que el aumento de valor de esta tenga repercusión alguna en las cuentas de capital de los socios de la cooperativa.

Así, tenemos que la filial de la cooperativa constituida bajo fórmula mercantil en otro país (cabe aplicarlo a las constituidas en el mismo) y que genera beneficios puede no tener efecto alguno sobre la liquidación del socio en caso de baja. 
Por el contrario, cuando se acuerde la distribución de dividendos o se venden las participaciones/acciones representativas, la sociedad generará la plusvalía, que se integrará en las cuentas ordinarias del ejercicio de la cooperativa. Esto es, criterios contables, pensados básicamente para las sociedades mercantiles, en los que el valor de las acciones/participaciones no es el nominativo sino el del mercado, determinarán el valor de la aportación a reintegrar al socio que en el caso de las cooperativas si es la nominativa que aparezca en las cartillas o en los títulos equivalentes.

Cuando se constituye una empresa es necesario capitalizarla y que se desarrolle, resultando habitual que cuando se empiezan a obtener resultados o cuando se proceda a realizar desinversiones habrá trascurrido un número de años. Durante ellos la inversión no habrá tenido ningún efecto positivo sobre las cuentas la cooperativa, siendo muy posible que algunos socios se hayan jubilado y que otros nuevos hayan incorporado.

Pues bien, con el actual sistema aquellos socios que lo eran cuando se constituyó la filial y se jubilaron antes de la floración de los resultados, o del mero acuerdo de repatriación de dividendos, no participaran en absoluto de los mismos, mientras que aquellos socios que se han incorporado con posterioridad a su salida de la cooperativa si tendrán derecho a participar de los mismos.

Creemos que el fenómeno merece cierta reflexión y que no responde de forma adecuada a la actividad cooperativizada. Incorporándose el resultado a las cuentas de un ejercicio, se distribuirá el mismo en base a la actividad cooperativizada realizada por los socios que lo sean en ese ejercicio.

Con el sistema tradicional estos resultados se hubiesen integrado en fondos obligatorios. Con el sistema actual se distribuyen entre aquellos que lo son el momento de la distribución y en base a la actividad del año de distribución.

Creemos debería reflexionarse sobre la conveniencia de posibilitar una participación en esos resultados proporcional a un periodo generación más amplio, en base a la actividad cooperativizada la durante ese periodo generación y reflexionarse sobre la posible participación de los que fueron socios durante el periodo, proporcional a la actividad cooperativizada de todo el periodo de generación.

Subyace, en cualquier caso, la cuestión de si el problema de fondo es que estamos realizando actividad extra cooperativa a través de una cooperativa. En ese sentido, una posibilidad para hacer partícipe a los socios de los resultados de la mercantil sería crear una especie de holding mercantil que fuera a la que realmente realizara la actividad ex- 
tra cooperativa, constituyendo una nueva empresa filial en el extranjero, de la que los socios de la cooperativa sean socios directos. De esta forma se estaría jugando con reglas no cooperativas respecto de una actividad no cooperativizada.

Existen por tanto diversas posibilidades y creo necesario que se debe debatir sobre cuál puede ser la más adecuada para resolver situaciones, como la de aquel socio que tras 40 años en una cooperativa, que se había internacionalizado, disponiendo de plantas en cinco países no tiene participación alguna en el valor de las mismas, mientras que el socio que se incorpora al año de su jubilación, con la fortuna de venderse una de las plantas, acaba participando en el resultado.

\section{Efectos de las ventas de activos antes o después de acordar la liquidación}

Se trata aquí de analizar el distinto efecto de que la venta del activo con plusvalías (no teniendo la cooperativa pérdidas que las compensen) se realice antes o después de un acuerdo de liquidación.

Antes hemos analizado como en el actual sistema la plusvalía por la venta del activo se integra dentro los resultados del ejercicio. Si la cooperativa no perdía dinero antes de la venta, el resultado de la venta será positivo generando los obligatorios fondos (mínimo un 30\%) y pudiendo distribuirse la restante cantidad.

La ley vasca regula la adjudicación del haber social en el artículo 94 y, en general, la disolución y liquidación de su artículo 87 al 96.

Realizadas por los liquidadores las operaciones necesarias de liquidación, la adjudicación del haber social se realizará de la siguiente manera:

«Artículo 94. Adjudicación del haber social.

1. No se podrá adjudicar ni repartir el haber social hasta que no se hayan satisfecho íntegramente las deudas sociales, se haya procedido a su consignación o se haya asegurado el pago de los créditos no vencidos.

2. Satisfechas dichas deudas, el resto del haber social se adjudicará por el siguiente orden:

a) La contribución para educación y promoción cooperativa y otros fines de interés público se pondrá a disposición del Consejo Superior de Cooperativas de Euskadi.

b) Se reintegrará a los socios el importe de las aportaciones que tuvieran al capital social, actualizadas en su caso, comenzando por las aportaciones voluntarias y siguiendo con las aportaciones obligatorias. 
c) Se reintegrará a los socios su participación en los fondos de reserva voluntarios que tengan carácter repartible por disposición estatutaria o por acuerdo de la Asamblea General, distribuyéndose los mismos de conformidad con las reglas establecidas en Estatutos o en dicho acuerdo y, en su defecto, en proporción a las operaciones, servicios o actividades realizadas por cada uno de los socios con la cooperativa durante los últimos cinco años o, para las cooperativas cuya duración hubiese sido inferior a este plazo, desde su constitución.

d) El sobrante, si lo hubiera, tanto del Fondo de Reserva Obligatorio como del haber líquido de la cooperativa, se pondrá a disposición del Consejo Superior de Cooperativas de Euskadi, salvo lo dispuesto en el artículo 132 para las cooperativas de segundo o ulterior grado.

3. Mientras no se reembolsen las aportaciones previstas en el artículo 57.1.b, los titulares que hubieran causado baja y a los que la cooperativa hubiera rehusado el reembolso participarán en la adjudicación del haber social, después de la contribución para educación y promoción cooperativa y otros fines de interés público y, salvo que los estatutos sociales prevean lo contrario, antes del reintegro de las demás aportaciones.»

Esto es, la realización de activos antes del acuerdo de liquidación se integraría dentro de las cuentas anuales del ejercicio y, de no existir pérdidas a compensar, daría lugar a una generación de fondos obligatorios por un mínimo del 30\% y a la posibilidad de distribuir el $70 \%$ restante entre los socios.

Por el contrario, la realización de los mismos activos dentro un proceso de liquidación, significaría que, de poderse atender con los restantes bienes a las letras a, b y c del número uno del artículo 94, generarían haber líquido que debería ser entregado al Consejo Superior de Cooperativas de Euskadi.

Creemos que debiera discutirse si la misma decisión adoptada antes o después de un acuerdo formal de liquidación debe conllevar tan distintas consecuencias económicas.

\section{Contabilidad y ajustes en patrimonio}

La Norma de Registro y Valoración 22 (NRV22) del PGC (en el PGCPYMES la NRV21) desarrolla los criterios expuestos en la NIC8 (Políticas contables, cambios en las estimaciones contables y errores):

\footnotetext{
«CAMBIOS EN CRITERIOS CONTABLES, ERRORES Y ESTIMACIONES CONTABLES

Cuando se produzca un cambio de criterio contable, que sólo procederá de acuerdo con lo establecido en el principio de uni-
} 
formidad, se aplicará de forma retroactiva y su efecto se calculará desde el ejercicio más antiguo para el que se disponga de información.

El ingreso o gasto correspondiente a ejercicios anteriores que se derive de dicha aplicación motivará, en el ejercicio en que se produce el cambio de criterio, el correspondiente ajuste por el efecto acumulado de las variaciones de los activos y pasivos, el cual se imputará directamente en el patrimonio neto, en concreto, en una partida de reservas salvo que afectara a un gasto o un ingreso que se imputó en los ejercicios previos directamente en otra partida del patrimonio neto.» (el subrayado es mío).

Esto es, por norma contable se establece que ciertos ingresos o gastos correspondientes a años anteriores (nos remitimos a la propia norma) deben ser imputados directamente en el patrimonio neto. Se rompe así con el tradicional criterio de aprobación de cuentas anuales, en la que hay una cuenta de resultados para aprobar y distribuir, incorporándose alguna de las partidas directamente sobre el patrimonio.

Si en una sociedad mercantil los ajustes al patrimonio tienen un impacto directo en el valor de la acción/participación, siendo homogéneo para cada una de ellas, resulta que en una cooperativa es preciso realizar un acuerdo expreso sobre el ajuste patrimonial, a fin de determinar el efecto del ajuste sobre las posibles distintos destinos de un resultado ordinario (imputar el ajuste). Si el ajuste es negativo resultarán unas pérdidas que habrá que imputar y si es positivo unos resultados que habrá que distribuir. El ajuste patrimonial puede ser contra cualquiera de las cuentas del patrimonio de la cooperativa.

Un problema adicional resulta de que el ajuste se realiza en el patrimonio, y no en la cuenta de resultados, por entenderse que corresponde a ejercicios anteriores. Se abren así otras discusiones como: si la imputación conforme a la actividad cooperativizada del ejercicio es correcta o debiera realizarse conforme a la actividad cooperativizada del periodo en que se genera o que pasa con los socios que han causado baja (si deben participar o si deben ser excluidos).

En la actualidad no hay ninguna regulación específica cooperativa que contemple la cuestión, debiéndose realizar una interpretación analógica de lo dispuesto en los artículos 67 y 69, y adoptarse un acuerdo expreso de la Asamblea General relativo al destino del ajuste patrimonial.

De nuevo, creemos conveniente un debate sobre la posible necesidad de regular la cuestión. 


\section{Repartibilidad de fondos constituidos por estatutos o acuerdo de Asamblea General como irrepartibles}

Durante muchos años he vivido con el convencimiento de que los fondos que estatutariamente son irrepartibles o sobre los que la Asamblea General ha acordado su irrepartibilidad eran irrepartibles.

No obstante, en los últimos años, he visto como algunas cooperativas han procedido a discutir o acordar la repartibilidad de fondos que eran voluntariamente irrepartibles (por estatutos o por acuerdo de Asamblea). La argumentación es que si no son repartibles por un acuerdo estatutario, cabe modificar los estatutos y si no lo son por un acuerdo de Asamblea General cabe que la Asamblea General tome un acuerdo en sentido contrario.

La lógica jurídica de la propuesta es clara, quien puede adoptar la decisión puede cambiarla.

No obstante, hay aspectos adicionales que creo que deben ser considerados y que deberían debatirse al objeto de considerar si es preciso su regulación específica.

Por un lado, tenemos socios que han podido dejar de serlo entre momento de la dotación del fondo y el momento del reparto. Hay socios que causaron baja y en cuya liquidación no se consideraron estos fondos

Por otro, tenemos una vez más que si se reparte en base a la actividad cooperativizada del último ejercicio, existirán socios que no los constituyeron y, sin embargo, se benefician de ellos.

Además, conforme a las reglas de liquidación, tendríamos que de considerar repartible el fondo y poderse cubrir las demás partidas previstas para la adjudicación del haber social, articulo 94, el destinatario de estos fondos irrepartibles sería el Consejo Superior de Cooperativas de Euskadi. Consejo que podría tener un interés legítimo y verse perjudicado por la modificación del acuerdo (sin perjuicio de la discusión jurídica sobre si su derecho nacería con la adopción del acuerdo de constitución del fondo irrepartible o sólo cuando se adopta el de disolución).

Por último, tenemos que en caso de adoptarse el acuerdo por la Asamblea General, es poco probable que los socios beneficiarios del mismo tengan un interés en impugnarlo (al beneficiarles) y no existen mecanismos que permitiesen al Consejo Superior de Cooperativas de Euskadi, en caso de considerar que tuviese un interés legítimo en la impugnación del acuerdo, tener conocimiento del mismo.

Una variante del anterior, que afecta sólo a exsocios y no al CSCE es la de aquellos fondos de reserva repartibles bajo ciertas condiciones 
(por ejemplo transcurridos cinco años desde su constitución) que pueden acabar repartidos entre socios que no lo eran en el momento de su constitución y del que son excluidos aquellos que lo eran en ese momento y que habían contribuido con su actividad cooperativista al resultado.

Una vez más considero que las consecuencia de la actual regulación deben ser discutidas y, en su caso modificarse.

\section{Problemas de descapitalización derivados de jubilaciones de socios trabajadores. Necesidades de capital para el establecimiento de cooperativas de trabajo asociado industriales fuertes}

Uno de los tradicionales problemas de las sociedades cooperativas de trabajo asociado es el capital del que pueden disponer los socios trabajadores para aportar a la cooperativa en la que se integran. Usualmente, contra más joven sea el trabajador menos ahorro habrá reunido y, por tanto, menor será su capacidad de aportar capital a la cooperativa.

Las cooperativas industriales vascas tienen una pirámide demográfica similar a la del resto de la sociedad. Existe un colectivo de socios de la generación del «baby boom» próximo jubilarse con unas cartillas generadas en los períodos económicamente buenos, muy altas.

Resulta por tanto complejo sustituir socios veteranos con capitales altos por socios jóvenes con capitales bajos. El recambio exige la cobertura de las diferencias de capital mediante fondos irrepartibles (con lo que supone a renuncia de retornos de los socios actuales) o mediante financiación externa.

Las diversas reformas de la Ley de Cooperativas de Euskadi han intentado resolver este punto abriendo posibles fuentes de financiación. La posibilidad de rehusabilidad del capital social vienen también a poder ser un instrumento para mitigar el problema.

No obstante, el tema no está resuelto.

Si la mortandad de las sociedades de capital se cubre con nuevos nacimientos de sociedades que van creciendo, en el caso cooperativo industrial es casi imposible la creación ex novo de una sociedad que exija una alta concentración de capital por cada puesto de trabajo. A mayor intensidad de capital por puesto de trabajo, será más difícil su cobertura por el sistema cooperativo, salvo que la creación se apoye en otra cooperativa preexistente.

A futuro, puede ser el principal problema a resolver, especialmente en un momento de relevo generacional. 


\section{Transformación y homologación}

Reconocida expresamente la posibilidad por la LCE, se regula de la siguiente manera:

«Artículo 85. Transformación de cooperativas.

1. Las cooperativas podrán transformarse en sociedades civiles o mercantiles de cualquier clase siempre que se cumplan los requisitos siguientes:

a) La transformación sólo podrá efectuarse por necesidades empresariales que exijan soluciones societarias inviables en el sistema jurídico cooperativo, a juicio de los administradores y, en su caso, de la Comisión de Vigilancia de la cooperativa, homologado por el Consejo Superior de Cooperativas de Euskadi.

b) Habrá de recaer acuerdo, expreso y favorable, de la Asamblea General, adoptado con los requisitos establecidos para modificar los Estatutos.

c) El acuerdo de la Asamblea deberá publicarse en el Boletín Oficial del País Vasco y en dos periódicos de gran circulación en el territorio histórico en que la cooperativa tenga su domicilio.

d) La escritura pública de transformación incluirá todas las menciones legal y reglamentariamente exigidas para la constitución de la entidad cuya forma se adopte, respetando lo dispuesto en la presente ley. El informe de los expertos independientes sobre el patrimonio social no dinerario, previsto en la legislación mercantil, se incorporará, en su caso, a dicha escritura.

e) Dicha escritura pública habrá de ser presentada, sucesivamente, tanto en el Registro de Cooperativas, para inscribir la baja correspondiente, como, en su caso, en el Registro Mercantil para la inscripción primera de la entidad cuya forma se adopte. Dicha escritura irá acompañada del balance cerrado el día anterior al del acuerdo de transformación o bien al finalizar el último ejercicio, si hubieren transcurrido menos de seis meses desde el cierre del mismo y hubiese sido depositado en el domicilio social a disposición de los socios desde el mismo día en que se cursó la convocatoria de la Asamblea General.

También se relacionarán los socios que hayan ejercitado el derecho de separación y el capital que representen, así como el balance final elaborado por los administradores y cerrado el día anterior al otorgamiento de la escritura.

2. La transformación no afecta a la personalidad jurídica de la cooperativa transformada, que continuará subsistiendo bajo su nueva forma.

3. Tendrán derecho de separación los socios que hayan votado en contra en el acto de la Asamblea, o los que, no habiendo asistido a la Asamblea, expresen su disconformidad mediante escrito dirigido a los administradores en el plazo de cuarenta días desde la publicación del 
último anuncio del acuerdo. Tales socios tendrán derecho al reembolso de sus aportaciones al capital en el plazo que, sin exceder del previsto en el artículo 63 y desde la fecha del acuerdo de transformación, determinen los Estatutos o acuerde la Asamblea, percibiendo el interés legal del dinero por las cantidades aplazadas.

4. El valor nominal de las dotaciones del Fondo de Reserva Obligatorio y de las reservas voluntarias irrepartibles se acreditará al Consejo Superior de Cooperativas de Euskadi como títulos de cuentas en participación referidos a la sociedad resultante del proceso transformador, debiendo adoptar la oportuna decisión la misma Asamblea que acuerde la transformación.

La contribución para educación y promoción cooperativa y otros fines de interés público tendrá la aplicación estatutariamente prevista y, en su defecto, la establecida en el apartado a) del número 2 del artículo 94 para el supuesto de liquidación de la cooperativa.

5. Al aprobar la transformación, la Asamblea General podrá optar por convertir las aportaciones al capital social en participaciones económicas de la nueva entidad en proporción directa al capital que tuviere desembolsado cada socio en la cooperativa al derecho de voto que ostentaba en la misma cooperativa, o bien combinando ambos criterios.»

En la estatal se regula de una forma más limitada, artículo 69:

«6. En el supuesto de transformación de una sociedad cooperativa en otro tipo de entidad, los saldos de los fondos de reserva obligatorio, el fondo de educación y cualesquiera otro fondo o reservas que estatutariamente no sean repartibles entre los socios, recibirán el destino previsto en el artículo 75 de esta Ley para el caso de liquidación de la cooperativa.»

Dos son las cuestiones que quiero comentar.

La primera, de relativa al acuerdo de homologación exigido por la LCE. Transformación por «necesidades empresariales que exijan soluciones societarias inviables en el sistema jurídico cooperativo». Las causas han sido fijadas fijado por acuerdo del Consejo Superior de Cooperativas de Euskadi, ganado así en seguridad jurídica.

Para mí la pregunta es si la decisión sobre un cambio de fórmula jurídica debe estar basada en necesidades empresariales que exijan soluciones societarias inviables en el sistema jurídico cooperativo. O, dicho de otra manera, cual es el motivo por el que los socios son libres de elegir el sistema jurídico cooperativo pero no son libres para cambiar dicha fórmula. ¿Acaso el cooperativismo, desde un punto de vista jurídico, no es una mera forma del derecho sociedades? 
¿Condicionar la salida, no implica negar, respecto del colectivo, el principio de puerta abierta?

La segunda las cuestiones, afecta a ambas normas y está relacionada con los efectos económicos derivados de la transformación de la cooperativa en otra fórmula jurídica. La cuestión que voy a introducir va a repetir en muchos de los puntos siguientes que comentaré. Las peculiaridades del régimen económico cooperativo respecto a las aportaciones de los socios y su reembolso nominal, hacen que si la cooperativa se transforma con plusvalías subyacentes en sus activos (aun no afloradas por no haber sido realizados), las mismas pasen directamente a los capitales de la nueva sociedad, sin generar fondos obligatorios. Si la transformación es a una sociedad mercantil, dichas plusvalías podrán ser valoradas del día siguiente de la transformación para determinar el valor de las acciones o participaciones de los socios. Además, se estará evitando lo previsto para los supuestos de disolución y liquidación como luego veremos.

Así, el hecho de transformar la cooperativa, posibilita a los socios hacerse propietarios «a título individual «de las plusvalías subyacentes. No nos parece mal, en cuanto que son suyas, pero si creemos que debe reflexionarse sobre una regulación jurídica que posibilita tan grandes diferencias económicas.

De hecho, existiendo plusvalías es claramente mejor, desde el punto de vista individual de los socios, proceder a una transformación y posterior liquidación que realizar directamente una liquidación. Las cantidades a recibir pueden ser sustancialmente distintas.

\section{Cambio de clase}

El cambio de clase de la cooperativa no recibe regulación específica.

En la LCE regula, en general, la clasificación y su normativa aplicable en su artículo 98:

«Artículo 98. Clasificación y normativa aplicable.

1. Las cooperativas pueden constituirse acogiéndose a cualquiera de las clases reguladas en el presente capítulo. Esa clasificación no obstará a la libre configuración estatutaria de otras cooperativas, con tal de que quede claramente determinada la correspondiente actividad cooperativa y la posición jurídica de los socios que deben participar en ella, en cuyo caso el Registro y los interesados aplicarán la normativa legalmente prevista para la clase de entidades con las que aquéllas guarden mayor analogía.

2. La delimitación legal de cada clase o tipo de cooperativas sólo impedirá la constitución de una entidad de segundo grado, de la 
clase respectiva, cuando los socios cooperadores tengan que ser, necesariamente y en su mayoría, personas físicas.

3. Cada cooperativa, además de ajustarse a los principios configuradores de esta sociedad en el marco de la presente ley, se regirá por las disposiciones especiales aplicables a la clase respectiva, y en lo no previsto en la sección correspondiente, por las normas de carácter general.»

La clasificación de la cooperativa puede ser de gran relevancia en cuanto que va a llevar aparejada la aplicación de una serie de disposiciones especiales específicas de la clase. Es una materia tan delicada como el propio objeto social al que muchas veces va vinculada.

No obstante, el cambio de clase puede ser realizado mediante una modificación de estatutos, con los requisitos propios de esta y sin que se establezca ninguna mayoría reforzada, ni se contemple un derecho de separación con devolución automática de las aportaciones.

Creo debería reflexionarse sobre la regulación de la cuestión, máxime en supuestos en los que la cooperativa está vinculada a un sector pero dependiendo de si se entiende de ese sector o de servicios al sector, los socios pueden tener diversas obligaciones. Similar cuestión puede plantearse de una cooperativa de trabajo asociado que próximos sus socios a jubilarse opten por pasar a consumo, modificando Estatutos para no verse obligados a realizar una disolución y liquidación.

\section{Cooperativas mixtas}

Novedad introducida por la Ley de Cooperativas de Euskadi de 1993 (artículo 136 LCE y DA 2. ${ }^{\text {a RRCE): }}$

"Artículo 136. Cooperativas mixtas.

1. Son cooperativas mixtas aquéllas en las que existen socios minoritarios cuyo derecho de voto en la Asamblea General se podrá determinar, de modo exclusivo o preferente, en función del capital aportado, que estará representado por medio de títulos o anotaciones en cuenta, sometidos a la legislación reguladora del mercado de valores.

2. En estas cooperativas el derecho de voto en la Asamblea General respetará la siguiente distribución:

a) Al menos el cincuenta y uno por ciento de los votos se atribuirá, en la proporción que definan los Estatutos, a socios cooperadores.

b) Una cuota máxima, a determinar estatutariamente, del cuarenta y nueve por ciento de los votos se distribuirá en partes sociales 
con voto, que, si los Estatutos lo prevén, podrán ser libremente negociables en el mercado.

3. En el caso de las partes sociales con voto, tanto los derechos y obligaciones de sus titulares como el régimen de las aportaciones se regularán por los Estatutos y, supletoriamente, por lo dispuesto en la legislación de sociedades anónimas para las acciones.

4. La participación de cada uno de los dos grupos de socios en los excedentes anuales a distribuir, sean positivos o negativos, se determinará en proporción al porcentaje de votos que cada uno de los dos colectivos ostente según lo previsto en el número 2.

Los excedentes imputables a los poseedores de partes sociales con voto se distribuirán entre ellos en proporción al capital desembolsado. Los excedentes imputables a los restantes socios se distribuirán entre éstos según los criterios generales definidos en esta ley para las cooperativas de régimen ordinario.

5. La validez de cualquier modificación autorreguladora que afecte a los derechos y obligaciones de alguno de los dos colectivos de socios requerirá el consentimiento mayoritario del grupo correspondiente, que podrá obtenerse mediante votación separada en la Asamblea General o en Junta especial y parcial (...)»

Y en la estatal:

«Artículo 107. Objeto y normas aplicables.

1. Son cooperativas mixtas aquéllas en las que existen socios cuyo derecho de voto en la Asamblea General se podrá determinar, de modo exclusivo o preferente, en función del capital aportado en las condiciones establecidas estatutariamente, que estará representado por medio de títulos o anotaciones en cuenta y que se denominarán partes sociales con voto, sometidos a la legislación reguladora del mercado de valores.

2. En estas cooperativas el derecho de voto en la Asamblea General respetará la siguiente distribución:

a) Al menos el 51 por 100 de los votos se atribuirá, en la proporción que definan los Estatutos, a socios cuyo derecho de voto viene determinado en el artículo 26 de esta Ley.

b) Una cuota máxima, a determinar estatutariamente, del 49 por 100 de los votos se distribuirá entre uno o varios socios titulares de partes sociales con voto, que, si los Estatutos lo prevén, podrán ser libremente negociables en el mercado y, por tanto, adquiribles también por los socios a que se refiere la letra a) anterior, a los que estatutariamente se les podrá otorgar un derecho de preferencia.

c) En ningún caso la suma total de los votos asignados a las partes sociales con voto y a los socios colaboradores podrá superar el 49 por 100 del total de votos sociales de la cooperativa. 
3. En el caso de las partes sociales con voto, tanto los derechos y obligaciones de sus titulares, como el régimen de las aportaciones, se regularán por los Estatutos y, supletoriamente, por lo dispuesto en la legislación de sociedades anónimas para las acciones.

4. La participación de cada uno de los dos grupos de socios en los excedentes anuales a distribuir, sean positivos o negativos, se determinará en proporción al porcentaje de votos que cada uno de los dos colectivos ostente según lo previsto en el número 2.

Los excedentes imputables a los poseedores de partes sociales con voto se distribuirán entre ellos en proporción al capital desembolsado. Los excedentes imputables a los restantes socios se distribuirán entre éstos según los criterios generales definidos en esta Ley.

5. La validez de cualquier modificación autorreguladora que afecte a los derechos y obligaciones de alguno de los colectivos de socios, requerirá el consentimiento mayoritario del grupo correspondiente, que podrá obtenerse mediante votación separada en la Asamblea General.»

\subsection{Porcentaje de capital y ajustes}

Hace ya 26 años cuando la LCE de 1993 introdujo, por primera vez, la figura, tuve la fortuna de comentarla con uno de los juristas que había participado en el Comité técnico elaborador del borrador de ley.

En aquel momento entendí que la cooperativa mixta significaba la posibilidad de mercantilizar un $49 \%$ del capital de la sociedad, con la exigencia de que el $51 \%$ restante siguiese en manos de socios cooperativistas, de que el control de la sociedad estuviese en manos de cooperativistas. El interés de la figura para el socio capitalista (en la línea prevista para las sociedades laborales respecto del capital en manos socios no laborales) sería que ese $49 \%$ podría incrementar su valor e inclusive llegar a cotizar en el mercado de valores.

No obstante, en este período ni una sola vez he trabajado con una cooperativa mixta que responda a este planteamiento (no pretendo afirmar que no las haya).

Por el contrario, en los últimos años me he venido encontrando con cooperativas mixtas, que me permito denominar de porcentajes de capital inestable o cuya variabilidad afecta, a través de la variación unilateral en la parte cooperativa, a ambos colectivos.

Tras la constitución inicial, la cooperativa, por definición de capital variable, ha ido modificando su capital, sea por la desinversión del socio capitalista en su parte del hasta $49 \%$, o más habitualmente, por la entrada de nuevos socios en la parte cooperativa (p.e. socios trabajadores) que han venido a alterar los porcentajes de capital. He venido ob- 
servando cómo los porcentajes de capital del socio capitalista pueden ser modificados por el aumento de participación en el capital de los socios cooperativistas. De esta forma se disminuye la participación total del socio capitalista en el posible reparto de excedentes, retornos y por otra, y de forma correlativa, se disminuye su derecho de voto.

Con este planteamiento, que puede ser lógico desde un punto de vista académico, es muy difícil que realmente un tercero ajeno al mundo cooperativo vaya tomar una participación del capital de la cooperativa, máxime cuando dicha participación y con ello sus derechos económicos y políticos van a quedar reducida al arbitrio de la parte cooperativista.

Problema adicional, es la determinación del momento en que se deben considerar los porcentajes de cara al ejercicio de los derechos políticos. En la práctica estoy observando una fijación anual de los porcentajes. Criterio que no encuentro basado en la norma sino en una cuestión práctica. Si atendemos a la variabilidad considero que el criterio debería ser el mismo que se usa para determinar que personas pueden asistir a la Asamblea General y ejercitar sus derechos de voto.

En cualquier caso, lo que parece evidente es que si no establecemos que la inversión capitalista da derecho a un porcentaje fijo de total de la cooperativa, de forma que cuando el capital de la parte cooperativista aumenta, se mantenga al porcentaje sin necesidad de incrementar el capital no cooperativo, nos encontramos con que mediante la simple admisión de nuevos socios, o inclusive, tal vez, de aportaciones voluntarias el Consejo rector puede diluir al socio no cooperativista.

Tal vez sea por ello, que la mayoría de las cooperativas mixtas con las que he trabajado hayan sido fundadas por otros cooperativas que inicialmente toman un porcentaje del capital mientras el proyecto se consolida y se incorporan más socios trabajadores y luego lo van reduciendo hasta salirse cuando la nueva crece lo suficiente. Suele ser un paso simultáneo a la integración de la que fue mixta en una cooperativa de segundo grado.

La otra cara del problema es cuando los socios cooperativos causan baja y el porcentaje del capitalista rebasa de hecho el porcentaje máximo. Si mantenemos el criterio de que se trata de otorgar un porcentaje inicial y no es precisa su adecuación, no existiría el problema. Si por el contrario entendemos que el porcentaje debe calcularse siempre sobre el real sólo podría a nivel teórico obligar a la parte cooperativa a aumentar su porcentaje o a la no cooperativa a disminuirlo. Esta segunda opción en circunstancias adversas será más teórica que práctica. 
Una vez más creo que la regulación peca de simplista en cuanto existen otras formas de control societario que pueden ser mucho más eficaces (rectores, directores, préstamos con condiciones de vencimiento en caso de cambio de administradores o directores, etc...). Posiblemente la regulación trata, simplemente, de posibilitar llegar hasta el límite de dejar de ser cooperativas y con ello de serle de aplicación la regulación vasca.

\subsection{Control mediante el socio colaborador}

Otra de las cuestiones problemáticas, que a mi juicio, plantean las cooperativas mixtas es el hecho de que el socio no cooperativista puede llegar a ostentar la mayoría de los derechos de voto y económicos a través de la figura del socio colaborador (por ejemplo mediante otra sociedad del grupo o mediante un directivo de aquella persona física).

$\mathrm{Ni}$ creo que era el propósito del legislador cuando se aprobó la posibilidad, ni creo que beneficie al cooperativismo y si creo que debería intentar afinarse la regulación.

\section{Cooperativización de empresas mercantiles filiales, normalmente en el extranjero, propiedad de la cooperativa}

Es frecuente, entre las cooperativas de trabajo asociado internacionalizadas vascas, que la propiedad de las filiales se ostente a través de fórmulas mercantiles de cada países en las que radican. Esta internacionalización ha permitido preservar los puestos de trabajo de las cooperativas vascas.

No obstante, creemos necesario reflexionar sobre si los límites que se establecen en las cooperativas vascas al empleo de trabajadores por cuenta ajena, deberán trasladarse a las filiales de esta y, especialmente en el caso que nos ocupa, de las filiales ubicadas en el extranjero.

Antes hablamos de las operaciones con terceros, hablábamos de constituir sociedades a través de las cuales realizar las operaciones con terceros y ahora queremos reflexionar brevemente sobre la problemática adicional generada cuando estas sociedades se encuentran en el extranjero.

Si bien la LCE prevé un crecimiento holding cooperativo a través de cooperativas de segundo y ulterior grado, lo cierto es que este crecimiento no permite un control absoluto sobre las cooperativas miem- 
bros que podrán según los acuerdos internos salir del mismo. La fórmula jurídica que mayor control permite es el establecimiento de una sociedad mercantil con tomo de la mayoría del capital.

Cuando se critica que la expansión cooperativa internacional se realice a través de fórmulas no cooperativas, se suele argumentar que no todos los países reconocen el modelo y/o que no en todos los países existe sensibilidad cooperativa que permita hacer socios a los trabajadores en las mismas condiciones y derechos que tendrían aquí.

Admitir esta segunda explicación, creo que supondría negar que el cooperativismo pueda ser universal. Los trabajadores no socios podrán necesitar una mayor o menor formación, incluso tener mayor o menor sensibilización cooperativa, pero no creemos que quepa rechazar la posibilidad de que pueden ser socios igual que los nuestros. Dar por hecho que esos trabajadores serán incapaces de asumir nuestros valores cooperativos es, en mi opinión, directamente contrario a los valores cooperativos.

Si las filiales están en otro país europeo, podríamos tal vez caminar hacia una cooperativa europea, pero cuando la filial está un país tercero puede ser más difícil encontrar la fórmula jurídica que nos permita integrar a esos socios junto a los nuestros, sin perder directamente el control de aquella inversión o el de nuestra propia sociedad cooperativa.

En este punto creemos que es preciso actualizar la regulación cooperativa tanto para intentar diseñar fórmulas que permitan que sus socios sean socios cooperativistas, como, en su caso, para establecer limitaciones al desarrollo de actividades no cooperativas. Si en la LCE, artículo 99.5, se prevén medidas a favor de los asalariados no socios y su posible incorporación como tales, cabe establecer medidas en el mismo sentido respecto de trabajadores que prestan sus servicios en sociedades mercantiles cuya mayoría de propiedad (cuando no son directamente unipersonales) recae en manos de cooperativas, a fin de favorecer la cooperativización de esas relaciones laborales. 